\title{
El término fragata en el paso del español clásico al moderno ${ }^{1}$
}

\author{
José Ramón Carriazo Ruiz \\ CILUS-Universidad de Salamanca
}

Con el descubrimiento de América y la conquista de las tierras del nuevo continente se hace patente en Castilla a principios del siglo XVI la necesidad de una gran flota. El auge de la construcción naval en el siglo XVI es asombroso. Cuando Felipe II cree los Reales Astilleros no hará sino poner bajo los auspicios de la Corona una manufactura técnica que ya se había desarrollado en el reinado de su padre en distintos puntos de la península.

Durante los primeros 50 años del siglo se produce un notable crecimiento del número de los estudiosos de la ciencia náutica; las grandes innovaciones técnicas que habían permitido a Cristóbal Colón realizar su viaje se generalizan, y la difusión del éxito de la empresa descubridora provoca el apasionado interés de muchos humanistas por esas novedades técnicas. La ciencia náutica se beneficia de este interés y de la constitución, a lo largo del siglo, de un corpus de conocimientos útiles y necesarios para la nueva empresa transatlántica ${ }^{2}$. En esta etapa muchos italianos (sobre todo genoveses) trabajan en España; Pedro Mártir de Anglería es uno de estos humanistas que, impresionados por los nuevos descubrimientos, escribe sobre ellos planteando en sus obras

1 Este trabajo está integrado en el proyecto PB97-1337, financiado por la DGICYT.

2 En este período se componen obras como las de Martín Fernández de Enciso (Suma de geografía, Sevilla, 1519) que ofrece una de las primeras descripciones del continente americano y Francisco Faleiro (Tratado de la Esphera y del Arte de Marear, Sevilla, 1535). 
cuestiones interesantes para la nueva técnica náutica ${ }^{3}$.

La normalización de la situación a lo largo del reinado de Felipe II pasa por el romanceamiento de todos estos conocimientos. Las necesidades de la Monarquía obligan a multiplicar el número de navíos al servicio de la Corona y también el número de personas que se dedican a gobernarlos. Estos oficiales desconocen el latín, pero necesitan conocimientos de cosmografía, construcción naval, navegación, astronomía, etc. En la segunda mitad del siglo aparecen abundantes tratados técnicos para uso de los que quieran navegar, se establecen estudios de navegación en Sevilla y la península se convierte en centro de la ciencia náutica a nivel europeo ${ }^{4}$.

Este proceso, que cronológicamente abarca desde la llegada de Colón a Castilla (1485) hasta la derrota de la Gran Armada (1588), tiene una importancia crucial para la historia de la lengua española: en estos años se constituye el vocabulario técnico náutico y naval del español clásico. Abundan los préstamos (sobre todo del italiano, como ha apuntado Terlingen, 1943, p. 245), con una adaptación rapidísima propia del gran uso que se da a los términos, importados por una necesidad designativa específica. La mayor parte de los tecnicismos náuticos del español clásico aparecen en la lengua en este momento.

Ése es el caso de la palabra que intentaré analizar en este trabajo.

3 Opera. Legatio Babylonica. Occeani decas. Poemata Epigrammata. (Sevilla, 1511). Esta obra contiene la primera de las De Orbe Novo Decades octo, la obra más popular del reinado del Emperador por lo que respecta a la difusión de la empresa descubridora y de los conocimientos náuticos. Apareció completa por primera vez en 1516, en Alcalá, y fue editada otras dos veces en la primera mitad del siglo (Basilea, 1521; Alcalá, 1530), con sus respectivas reimpresiones y traducciones (1532 al francés, 1534 al italiano, 1555 al inglés).

4 En este momento las ciencias náutica y naval alcanzan en España sus más altas cotas con la obra de Pedro de Medina. En 1545 salía de las prensas de F. Fernández de Córdova, en Valladolid, el más importante tratado de náutica del Renacimiento: el Arte de navegar. En 1553 se tradujo al francés, en 1554 aparece la versión italiana en Venecia, en 1581 la inglesa en Londres. El propio Pedro de Medina compone un resumen de su obra con fines prácticos: es el Regimiento de navegación (Sevilla, 1552).

5 "Le premier renseignement sérieux en ce qui concerne la construction des Frégates 
Fragata aparece por vez primera en español en 1535, en una carta que desde Nápoles escribe Juan de Valdés (Corominas-Pascual, 19801991, II, pp. 940-941); su forma y el texto en el que se documenta por vez primera no dejan dudas a los investigadores sobre su origen: es un claro italianismo en español (Terlingen, 1967, p. 285). Sobre la etimología de la voz parece que los autores no se ponen de acuerdo. Si, para unos, su origen estaría en el griego afraktos, 'sin puente, abierta, de bajo bordo' (Jal, 1848, I, pp. 718-720; Mayer, 1940, 219 y ss.); otros proponen el árabe harraqat 'barco incendiario' (Brüch, 1931, pp. 476 y ss.; Vidos, 1939, pp. 406-409); por fin Corominas-Pascual se inclinan por la expresión nau fragata como posible origen. En realidad la etimología no es relevante para los fines de este trabajo.

En italiano la voz tiene una historia muy peculiar: aparece por primera vez en 1350 en Boccaccio, atribuida a unos sicilianos, con la forma fregata; en 1369 se atestigua en Nápoles y pasa mucho tiempo hasta que se vuelve a documentar (cf. Battaglia, 1970, VI, p. 329). En tanto el término continúa su vida propia y pasa a todas las lenguas románicas: fr. 1521 fragate en un texto proveniente de Marsella, fregade en Rabelais, fragate en una traducción francesa del Amadis (cf. Gamillscheg, 1969, p. 450; Huguet, 1946, IV, p. 204); port. fragata en el siglo XVII (cf. Machado, 1977, III, p. 83); cat. fragata desde el siglo XVI (cf. Alcover-Moll, 1993, VI, p. 29; Aguiló y Fuster, 1921, Coromines, 1984, IV, pp. 160-161).

Todos los autores consultados coinciden en señalar que la voz fragata ha sufrido un cambio semántico en el siglo XVII. Así, Corominas, tanto en el $D C E C H$ como en el $D E C L C$, señala que las etimologías propuestas por Jal y Vidos son erróneas precisamente por basarse en el valor semántico contemporáneo de la voz y no en su significado primero. La inestabilidad de la designación de esta palabra a lo largo de la época en que se difundió constituye, posiblemente, el origen de la polémica en torno a su sentido primitivo.

De hecho, la historia semántica de fragata presenta peculiaridades más allá de la imposibilidad de determinar con precisión su etimología. En el reducido espacio temporal de apenas un siglo (el gran siglo de la navegación, eso sí) la voz se extiende a todas las lenguas romá- 
nicas de nuestro entorno, incluido el castellano. Se convierte, además, en nuestra lengua en una voz de gran uso y frecuencia, como atestigua su presencia en distintos diccionarios y vocabularios del momento (J. L.Palmireno, 1567, s.v. Navis monocrota; C. de las Casas, 1570, pág. 200; Sánchez de la Ballesta, 1575; Percivale, 1599; Oudin, 1607; Covarrubias, 1611). Se registra en cuatro ocasiones en las cartas de San Ignacio de Loyola, escritas desde Italia a mediados del XVI (15541556; vid. Monumenta Historica, 1908, doc. 4673, 1909, docs. 5502 y 5521, 1910, doc. 6210). Aparece también en Cervantes (Fernández Gómez, 1962, pág. 470), Lope (Fernández Gómez, 1971, II, p. 1259) y en Mateo Rosas de Oquendo (fregata, vid. Reyes, 1917, pp. 344 y ss.), lo que quiere decir que a finales de siglo ya había pasado a América. Durante todo este período la voz se aplica a una chalupa o pequeña embarcación que las galeras llevan amarrada a popa para saltar a tierra o usar en caso de naufragio. Covarrubias no deja dudas al respecto cuando la define como:

Batelejo que suele llevar consigo la galera, y la echa a la mar quando ay necesidad de llegar con ella a tierra, o ir de una galera en otra con algún recaudo, quasi fragmentum trirremis; por ser como una partezilla y miembro de la galera, uel a fragore, por el ruido que va haziendo con la presteza del bogar y menear de los remos; porque como es uajel pequeño va más ligero. Vel quia fragilis sit, porque no puede resistir a las olas del mar, si ay un poco de tormenta (Covarrubias, 1611, p. 557)

El mismo Jal habla de los dos significados históricos que tendría el término frégate (fragata en fr.a.): hasta el s. XVII la palabra se referiría a la menor de las naves de la familia de las galeras (naves sin bordo y con un sólo puente o ninguno), la más rápida y ligera. Sabemos que embarcaciones de este tipo intervinieron en el combate naval de Lepanto:

Las fragatas que se hallaren en la armada esten por popas de las galeras, y al tiempo de la batalla tengan dos esmeriles y diez arcabuceros, con un caporal para combatir con dos baxeles pequeños del enemigo (Vander Hammen, Don Juan de Austria, Madrid, 1627, apud Jal, I, p. 717).

Son, sin duda, naves pequeñas con poca artillería pero muy útiles en 
el auxilio de los navíos de mayor porte en medio de la batalla por su velocidad. Ésta es la primera referencia a una fragata de guerra que hemos podido encontrar, y es que el origen del cambio referencial que sufre la voz en el siglo XVII se gesta precisamente en el momento en el que se dota de artillería a este tipo de embarcaciones. Al armar la fragata para la guerra y aumentar su tonelaje, lo que antes era un batelejo o chalupa se va a transformar en un navío de alto bordo, con puente y batería de cañones. Debemos ahora preguntarnos con Jal: "A quelle époque et où fut construite la première frégate vaisseau?” (1848, I, p. 719).

La fragata, un barco pequeño de auxilio en el Mediterráneo a lo largo de la baja Edad Media, se adapta en el Renacimiento a la navegación atlántica y en el XVII comienza a utilizarse como navío militar independiente. La designación de fragata cambia; conserva el rasgo 'que navega a gran velocidad' pero deja de ser ligera para convertirse en un navío de alto bordo con tres palos y hasta tres baterías de cañones, ya en el siglo XVIII. El cambio se produce a lo largo del s. XVII en el Atlántico. Th. Fuller en su History of the Worthies of England, 1662, dice que en Dunkerque había fragatas amarradas ya en 1615 (Jal, I, p. 719). Las primeras documentaciones del nuevo significado aplicado a una palabra románica corresponde a la Romania Atlántica ${ }^{5}$. El término, como ya hemos expuesto, tuvo un origen mediterráneo: desde Sicilia se propagó al continente por Nápoles, Marsella y Cataluña 6 . A través del castellano el término llegó a Portugal (s. XVII) tras la unión de las flotas de ambos paises bajo la Corona de Felipe II.

En francés la voz presenta una vida muy azarosa a lo largo del siglo XVI: se registran numerosas variantes (frag $(u)$ ate, frég $(u)$ ate, fragade; cf. Vidos, 1939) y el significado es vago. En español, aunque hay una

faites sur les chantiers du Roy en France, est l'Estat abrégé de la mar. au ler janvier 1672 (Ms. Arch. de la Mar.)" (Jal, 1848, I, p. 719).

6 De hecho, es posible que la voz entrara en la Península Ibérica por vía del catalán si tenemos en cuenta las vacilaciones que se registran en la átona inicial, que en los tres idiomas peninsulares tiene [a] en lugar de [e], hecho éste que llevó a Brüch (1931, pp. 476 y ss.), a pensar que la expansión primera del vocablo tuvo por foco el catalán a partir de la conquista de Sicilia por los aragoneses.

7 En inglés se documenta la forma frigate en 1585 por vez primera, en un texto poético y con un significado anticuado; en 1630 aparece como tecnicismo con el nuevo sig- 
mayor uniformidad en las variantes, no aparece nada claro el significado sino es en Covarrubias. Rosas de Oquendo nos dice: "Desterróme y desterréme;/ metíme en una fragata:/ alsaron belas al viento,/ xunto con las de mis ansias" (cf. Reyes, 1917), de lo que sólo podemos concluir que se trataba de un barco a vela. Los ejemplos de Cervantes y de Lope tampoco nos ayudan demasiado a la hora de establecer con exactitud el significado de la palabra en el Siglo de Oro.

Esa indefinición semántica propia del español (aunque Covarrubias no la siente en absoluto) y del francés es consecuencia quizá de la polisemia de fragata en ambas lenguas a fines del s. XVI y durante todo el XVII. Se podría decir que en el s. XVII existían dos significados para la palabra fragata/fregate: por un lado el antiguo significado propio del Mediterráneo con el que la voz llegó al castellano y francés y, por otro, el derivado de las innovaciones que se habrían introducido en la embarcación al adaptarla a la guerra. La fragata mediterránea no era adecuada para la navegación atlántica precisamente por su debilidad (rasgo que le atribuye Covarrubias); sin embargo, el desarrollo de la piratería en el Caribe y buena parte del Atlántico durante la segunda mitad del siglo XVI había planteado como imperiosa la tarea de construir un barco de guerra (por tanto suficientemente grande para transportar artillería) pero al mismo tiempo muy ligero y rápido (características que todos los eruditos del Renacimiento, v.i. Palmireno, convienen en atribuir a la fragata del Mediterráneo). El resultado de la adaptación técnica a unas necesidades nuevas del viejo invento siciliano será el surgimiento de una nueva embarcación de alto bordo: la fragata atlántica.

En inglés no hay ningún problema para encontrar una denominación para la nueva nave, dado que se recurrirá a un préstamo románi$\mathrm{co}^{7}$. Ahora bien en la Romania, donde el término ya existía, el recurso más a mano es la introducción de una nueva acepción. Se produce el cambio semántico. El foco de irradiación del nuevo significado serán

nificado (cf. VV. AA., 1956, I, p. 752).

8 Donde el antiguo significado goza de buena salud entrado el siglo XVIII, como atestigua el Vocabolario degli Accademici della Crusca que, en 1738, define la Fregata como "Piccol navilio da remo". Bien es verdad que ya muestra indicios este diccio- 
las costas atlánticas de la Romania, en primer lugar Francia (1672), en segundo lugar España y Portugal, y por último Italia ${ }^{8}$.

En español la voz parece referirse hasta entrado el siglo XVII a una nave menor, parte de la galera, si damos crédito al testimonio de Covarrubias (v.s.). Según la documentación que he hallado creo poder afirmar, sin embargo, que a principios del XVII, al menos en determinados cÌrculos de germanía relacionados íntimamente con la navegación transatlántica, fragata era ya un barco conocido y de cierta envergadura (cf. los versos de Mateo Rosas de Oquendo). Teniendo en cuenta la fecha que da Jal para la invención de la Fragata atlántica en los astilleros ingleses (antes de 1615) parece imposible dar crédito al autor de la Sátira de las cosas que ocurren en el Pirú. Existe la posibilidad sin embargo de que Rosas de Oquendo estuviera al corriente de las innovaciones en la construcción naval al final de su vida cuando escribió su obra y que, aunque describe hechos de aprox.1590 (cuando se traslada de la península a América), utilizase el neologismo de sentido fregata para referirse al barco que lo transportó al Nuevo Continente. Si consideramos, por otro lado, que la forma que aparece en el texto corresponde exactamente a la forma del francés moderno parece aún más probable que el aventurero andaluz conociera el nuevo sentido y quizá prescinda de la forma usual para evitar la confusión (proceso que siguió el francés en su paso de la lengua medieval a la clásica al eliminar las variantes anteriores - frag(u)ata - cuando se fijó el nuevo significado).

nario de inestabilidad semántica en el término pues la entrada siguiente a fregata es fregatina ("Dim. di Fregata"). ¿Se trata, como dicen, de un inocente diminutivo de fregata; o se puede pensar más bien que su inclusión en el Vocabolario della Crus$c a$ es un indicio de su vida independiente, quizá como término aplicado al antiguo designatum de fregata? En cualquier caso, querría señalar aquí que el artículo del Grande Dizionario della Lingua italiana de Battaglia parece contradecirse con lo que nos dicen los propios académicos, pues Battaglia señala que ya en el s. XVII fregata significaba "nave da guerra della marina velica dotata de coperta e ponte di corridoio, attrezzata con tre alberi a vele quadre e armata con buon numero di cannoni" (1970, VI, p. 329).

9 En el Calepinus Septem Linguarum (Venecia, 1774) se explica el italiano fregata con las equivalencias latinas de celox y lembus (II, Vocabolario Italiano e Latino, p. 29). Si nos remitimos a la primera de ellas, ésta se define como: "f. 3. fregata, na- 
Sin embargo, sólo el estudio de las equivalencias latinas o inglesas (del Calepino 9 , Palmireno o Percivale) desde el punto de vista de la arqueología naval podría sacarnos totalmente de dudas. Por ejemplo, Juan Lorenzo Palmireno en su Lexicon nauticum et aquatile, de 1566, utiliza el término fragata para explicar el latino nauis monocrota del griego a su vez naus monokrotos. Según Jal (1848, II, p. 1015) la nauis monocrota es aquella que tiene una sola fila de remos, la más pequeña de las propulsadas a remos exactamente. Podemos por tanto decir que era una nave pequeña entre las de su tipo a mediados del XVI.

En el Quijote (I, II, $249 \mathrm{v}^{\mathrm{o}}$.) se registra por vez primera el sintagma fragata ligera iha surgido ya la necesidad de distinguir entre una cierta fragata y otra nave, fragata también, pero más pequeña?

El nuevo significado aparece por primera vez en una obra lexicográfica española en el Diccionario de Autoridades. Aparecen bajo la entrada fragata dos subentradas fragata de aviso y fragata ligera; el diccionario académico pone a continuación como entrada independiente fragatín. En estas voces técnicas, como en tantas otras de la obra, se observa la imprecisión que ya los contemporáneos achacaron a los académicos al definir los tecnicismos. Creo que es interesante reproducir el texto de la definición (elimino las autoridades):

FRAGATA.s.f. Baxél de guerra, à veces de alto bordo, que algunos llaman Navío afragatado, y à veces de baxo bordo, mui ligero, que regularmente no tiene mas que dos puentes.

\section{FRAGATA DE AVISO. Buque pequeño, que lleva algún paquete y aviso a las Armadas.}

vigii exigui genus quod uno remo tantum agitur, a celeritate, vel Graeca voce, quae allata est, quae sumpta est per methaphoram ab equo celeste, quia, ut hic ab uno regitur sessore, ita navigium istud unico tantum per transtra remo agitur. Est inventum Rhodiorum"(I, p. 125). Lembus, por su parte, se explica así: “m. brigantino, fregata, galeotta, naviculae exiguae genus, sed mirae velocitati, cujusmodi ante classem explorandi gratia solent praemitti...”(I, p. 422; la negrita es nuestra). 
FRAGATA LIGERA. fragata pequeña de solo un puente, montada de diez y seis à veinte piezas de cañón.

FRAGATÍN.s.m. Dim. de Fragáta. Fragáta pequeña (Real Academia, 1726-1735; la negrita es nuestra).

Todavía tiene mucha vitalidad el antiguo significado, el consignado por Covarrubias; la suficiente al menos para que los académicos consideren importante introducir la subacepción fragata de aviso. Es un dato importantísimo el que nos proporciona el Diccionario de Autoridades cuando dice que a la fragata de alto bordo "algunos llaman Navío afragatado". Evidentemente, la creación de una denominación sintagmática para un navío corresponde sin duda a la necesidad que tiene la lengua técnica de referirse a los denotata con precisión, evitando las ambigüedades que lógicamente se derivarían de la polisemia de "fragata" en el XVII. Lo mismo se podría decir para la locución fragata de aviso.

La, tan criticada en la época, imprecisión de las definiciones técnicas y científicas de la Academia en su Diccionario llevaron a muchos estudiosos del momento a interesarse por el vocabulario especializado. En parte con inquietudes de este tipo se enfrentó E. Terreros y Pando a la elaboración de su Diccionario Castellano. En él encontramos algunas diferencias con respecto a la definición académica, sobre todo por su precisión admirable, pues distingue perfectamente la fragata del Mediterráneo y la del Atlántico. Por ello me parece necesario reproducir íntegramente la definición del término que nos ocupa:

FRAGATA, navío pequeño, frecuente en el Mediterráneo. Fr. Fregate. Lat. Lembus celox, lubúrnica. It. Fregata. En el Oceano es un navío armado en guerra, por lo común con dos puentes, y á lo más monta 60 cañones. La Fragata lijera no monta sino de 16 à 25 cañones: hai fragatas que van a vela, y remo: en el uso común se le llama fragata a un navío de guerra, que tiene menos de 50 piezas de batir. Los pueblos de Liburnia usaron mucho esta especie de naves lijeras (Terreros, 1786-1793; la negrita es nuestra).

Por corresponder al significado más antiguo de la voz, el P. Terreros coloca en primer lugar la acepción 'navío pequeño'. Además, señala la 
segunda acepción como la ratificada por el uso común.

La Real Academia publica en 1783 una edición reducida del Diccionario de Autoridades, renunciando así a su antigua pretensión de reeditarlo ampliado. En este Diccionario de la Lengua Castellana, antecedente de nuestro DRAE, los Académicos reproducen con puntos y comas la definición de 1726-1735, con la única salvedad de la desaparición de las autoridades y de que el sintagma navio afragatado aparece en mayúscula.

En 1791 la Academia elimina de su Diccionario la subacepción fragata de aviso, la que recogía el significado clásico de la voz y la definición se rehace completamente:

FRAGATA.S.F. Embarcación de tres palos con cofas y una sola batera corrida de popa a proa. Liburnica. FRAGATA LIGERA. Fragata pequeña de un solo puente, montada de 16 a 20 piezas de cañón. celox, liburnica navis.

En esta fecha, por tanto, se da por finalizada la existencia de fragat $a$ 'nave pequeña que acompaña a otra mayor'. Por aquel entonces la galera, de la que la fragata había sido fiel compañera por el Mediterráneo hasta el XVII, también pasa a la historia (las últimas galeras de la flota española perecieron en Trafalgar en 1805). Finalmente, en 1803 desaparecer del diccionario académico la entrada correspondiente a fragatín.

BIBLIOGRAFÍA 
Aguiló y Fuster, M. (1914-1934): Diccionari Aguiló, Barcelona, IEC. Alcover, A. M. y Moll, F. B. (1993): Diccionari Català-Valencià-Balear, Forn-Llex, Palma de Mallorca, Moll.

Battaglia, S. (1970): Grande Dizionario della lingua Italiana, Turín, Unione tipografico-editrice torinese.

BRÜCH (1931): ZFSL, LII, pp. 476 y ss.

CASAS, C. de las (1570): Vocabulario de las dos lenguas toscana y castellana, Sevilla (ed. Facsímil, Madrid, Istmo, 1988).

Corominas, J. y Pascual, J. A. (1980-1991): Diccionario Crítico Etimológico Castellano e Hispánico, Madrid, Gredos.

CoRomines, J. (1984): Diccionari etimologic i complementari de la Llengua Catalana, Barcelona, Curial-Caixa de Pensions.

Covarrubias, S. (1611): Tesoro de la Lengua castellana o española, ed. de F. C. R. Maldonado Madrid, Castalia, 1995.

FERnÁndez Gómez, C. (1962): Vocabulario de Cervantes, Madrid, Real Academia Española.

Fernández Gómez, C. (1971): Vocabulario de Lope de Vega, Madrid, Real Academia Española.

GAMILLSCHEG, E. (1969): Etymologisches Wörterbuch der Französischen Sprache, Heidelberg, Universitätsverlag.

Huguet, E. (1946): Dictionnaire de la Langue Française du XVI e siècle, París, Librerie M. Didier.

JAL, A. (1848): Glossaire Nautique, París, L'Institut de France.

Machado, J. P. (1967): Dicionário Etimológico da lingua Portuguesa, Lisboa, Livros Horizonte.

MAYeR, G. (1940): Vox Romanica, V, pp. 219 y ss.

Monumenta Historica Societati Iesu (1908-1910), Monumenta Ignatiana, Epistolae et Instructiones, Madrid, Societas Iesu, vols. 7 (1908), 9 (1909) y 10 (1910).

Palmireno, J. L. (1566): Lexicon nauticum et aquatile, en Tertia pars Rhetoricae Laurentii Palmyreni, Valencia, Ioannis Mey.

Reyes, A. (1917): "Sobre Mateo Rosas de Oquendo", RFE, IV, pp. 341370.

TERLINGEn, J. (1943): Los italianismos en español desde la formación del idioma hasta principios del s. XVIII, Amsterdam, N.V. Hollandsche 
Uitgevern Maatszhappij.

Terreros, E. (1786-1793): Diccionario Castellano con las voces de Ciencias y Artes, Madrid, Ibarra.

Vidos, B.E. (1939): Storia delle parole marinaresche Italiane passate in Francese, Florencia, Leo S. Olschki.

VV. AA. (1956): The Shorter Oxford English Dictionary, Oxford, Clarendon Press, 3rd edition with addenda. 